ORNL/TM-2003/24

\title{
REPORT on the \\ TRUCK BRAKE LINING WORKSHOP and FLEET OPERATORS' SURVEY
}

\section{Technology and Maintenance Council (TMC), 2002 Fall Meeting Charlotte, North Carolina}

December 2, 2002

\author{
prepared for \\ U.S. Department of Transportation \\ National Highway Traffic Safety Administration \\ Washington, DC \\ by \\ Peter J. Blau \\ Metals and Ceramics Division \\ Oak Ridge National Laboratory \\ Oak Ridge, Tennessee
}

This project is sponsored by the U.S. Department of Transportation under interagency agreement DOE 2334-R486-A1 with the US Department of Energy under contact DE-AC05-00OR22725 with UTBattelle, LLC. Distribution is unlimited. 


\section{Preface}

This report comprises part of a project conducted by staff members of the Metals and Ceramics Division, Oak Ridge National Laboratory, at the request of the U.S. Department of Transportation, National Highway Traffic Safety Administration (NHTSA), C. J. Britell, Project Manager. The purpose of the work is to develop guidelines and recommendations aimed at establishing a practical rating system for heavy truck brake linings, particularly those used to select aftermarket, replacement linings. The complexity of the underlying engineering challenge has resulted in efforts extending over the last thirty years. Reaching a practical solution has been complicated by issues like the selection of the appropriate testing protocols, the scale of testing required (ranging from full-sized vehicles to laboratory apparatus), the repeatability and reproduciblilty of test data, and the considerable investments of groups like the Society of Automotive Engineers (SAE) Brake Linings Committee, the Heavy Duty Brake Manufacturers Council, domestic brake lining manufacturers, testing laboratories, and the American Trucking Associations. There is strong advocacy for this project among fleet owners and operators, but there is also a range of opinions on what form such a rating system should take and how lining ratings should be measured and used.

Oak Ridge National Laboratory has been studying this issue from the viewpoint of an objective third party. The first steps in that process involve information gathering from a variety of sources, including industry groups, like the Technology and Maintenance Council (TMC). With the cooperation of Robert Braswell, TMC Technical Director, and Joseph Stianche, Sanderson Farms, Inc., Chairman of TMC Task Force S6 (Chassis), a special workshop was organized. The title was "Developing a Useful Friction Material Rating System." The workshop was held on October 17, 2002, in conjunction with the TMC Fall Meeting in Charlotte, NC. It consisted of a panel of presenters and an afternoon break-out discussion session. In addition to the workshop, and to supply additional information, a written survey form was provided to fleet operators at the meeting. The survey was developed with input from members of the Heavy Duty Brake Manufacturers Council and NHTSA. The purpose of this report is to summarize the opinions expressed during discussions and survey taken at the TMC fall meeting.

Peter J. Blau

Metals and Ceramics Division

Oak Ridge National Laboratory

November 2002 


\section{CONTENTS}

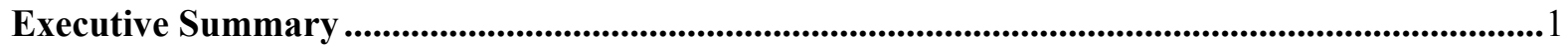

$1.0 \quad$ Summary of Invited Talks.........................................................................................................

2.0 Summary of Afternoon Break-out Session Discussions............................................................6

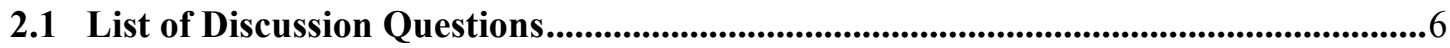

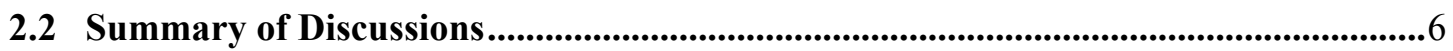

3.0 Fleet Operators Survey..................................................................................................................... 10

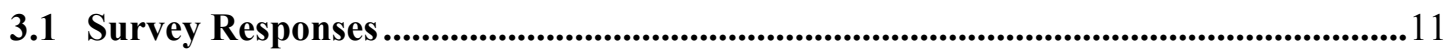

3.2 Additional Comments Regarding RP 628...................................................................... 14

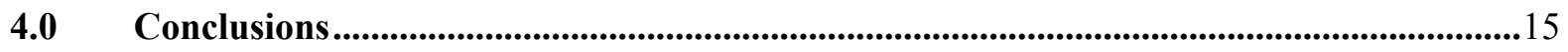

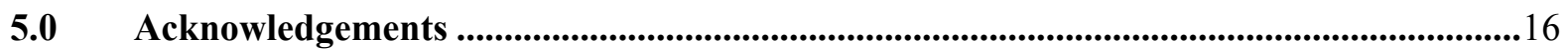

Appendix A: Discussion Group Members ............................................................................................17

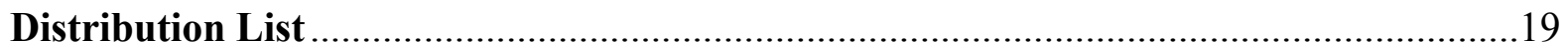




\section{Executive Summary}

The report summarizes what transpired during brake linings-related workshop held at the Fall 2003 meeting of the Technology and Maintenance Council (TMC) in Charlotte, NC. The title of the workshop was "Developing a Useful Friction Material Rating System." It was organized by a team consisting of Peter Blau (Oak Ridge National Laboratory), Jim Britell (National Highway Traffic Safety Administration), and Jim Lawrence (Motor and Equipment Manufacturers Association). The workshop was held under the auspices of TMC Task Force S6 (Chassis), chaired by Joseph Stianche (Sanderson Farms, Inc.).

Six invited speakers during the morning session provided varied perspectives on testing and rating aftermarket automotive and truck brake linings. They were: James R. Clark, Chief Engineer, Foundation Brakes and Wheel Equipment, Dana Corporation, Spicer Heavy Axle and Brake Division; Charles W. Greening, Jr, President, Greening Test Labs; Tim Duncan, General Manager, Link Testing Services;Dennis J. McNichol, President, Dennis NationaLease; Jim Fajerski, Business Manager, OE Sales and Applications Engineering, Federal Mogul Corporation; and Peter J. Blau, Senior Materials Development Engineer, Oak Ridge National Laboratory.

The afternoon break-out sessions addressed nine questions concerning such issues as: 'Should the federal government regulate aftermarket lining quality?; 'How many operators use RP 628, and if so, what's good or bad about it?; and 'Would there be any value to you of a vocation-specific rating system?' The opinions of each discussion group, consisting of 7-9 participants, were reported and consolidated in summary findings on each question. Some questions produced a greater degree of agreement than others. In general, the industry seems eager for more information that would allow those who are responsible for maintaining truck brakes to make better, more informed choices on aftermarket linings.

A written fleet operator survey was also conducted during the TMC meeting. Twenty-one responses were received, spanning fleet sizes between 12 and 170,000 vehicles. Responses are summarized in a series of tables separated into responses from small (100 or fewer powered vehicles), medium (101 - 1000 vehicles), and large fleets ( $>1000$ vehicles). The vast majority of fleets do their own brake maintenance, relying primarily on experience and lining manufactures to select aftermarket linings. At least half of the responders are familiar to some extent with TMC Recommended Practice 628 on brake linings, but most do not use this source of test data as the sole criterion to select linings. Significant shortfalls in the applicability of TMC RP 628 to certain types of brake systems were noted. 


\subsection{Summary of Invited Talks}

The special session on "Developing a Useful Friction Material Rating System" began at 9:45 am on October 17 with approximately 85 persons in attendance. The invited speakers were selected to represent a cross-section of truck equipment manufactures, testing laboratory managers, fleet operators, and friction material suppliers. The meeting chairman was Joseph Stianche, Sanderson Farms, Inc., in-coming Chairman of the Technology and Maintenance Council (TMC) Task Force S6 - Chassis. The following presentations were given in the morning session. Copies of the presentation materials are available separately.

Welcome and Introductions - Joseph Stianche, Fleet Manager, Sanderson Farms, Inc., Chairman TMC S6

Current Aftermarket Rating Systems - Recommended Practice RP 628

James R. Clark, Chief Engineer, Foundation Brakes and Wheel Equipment, Dana Corporation, Spicer Heavy Axle and Brake Division

Current Rating Systems for Replacement Brake Linings

Charles W. Greening, Jr, President, Greening Test Labs

Lessons Learned from the Brake Manufacture Council's 'Passenger Car and Light Truck Voluntary

Friction Certification Program'

Tim Duncan, General Manager, Link Testing Services

Brake Lining Selection: A Fleet Operator's Perspective

Dennis J. McNichol, President, Dennis NationaLease

Predicting Lining Performance

Jim Fajerski, Business Manager, OE Sales and Applications Engineering, Federal Mogul Corporation

An Approach Toward the Development of a Practical Friction Material Rating System

Peter J. Blau, Senior Materials Development Engineer, Oak Ridge National Laboratory

Presentation by James Clark. Mr. Clark's presentation began with an overview of several truck brake testing procedures, the equipment used, and criteria used to evaluate the results. He indicated that on a typical tractor-trailer combination, over $90 \%$ of the braking power came from the drive and trailer axle brakes. There was a particular discussion of the historical development and use of TMC Recommended Practice 628 for S-cam drum brakes. It was shown how results are evaluated and published. Results of these tests are published two weeks after submittal on the PRI website (http://www.pri.sae.org-NADCAPbrakerep.pdf). Clark discussed the relationship between TMC, SAE, and the Performance Review Institute, an SAE subsidiary in conducting RP 628 and ensuring that it complies with FMVSS 121. The number of linings on the RP 628 list have increased over the years from 4 in 1994 to about 50 in 2002. Torque values for different chamber sizes and axle ratings were compared. Several linings over the years 
have been challenged and of those, some were removed from the list. The need to address other types of brakes (air and hydraulic disc, etc.) and other wheel sizes was indicated. New procedures could be added to RP 628 and a full set of test parameters and results (torque at $40 \mathrm{psi}$ ) would be published. The market should dictate supplier submissions. He concluded with the following suggestions regarding a new lining system, including federal rulemaking:

(a) Require the exact lining formula that was on the new vehicle as the replacement lining.

(b) Require suppliers to certify the parameters that each aftermarket lining product must have to meet FMVSS 121 dynamometer test requirements (axle load, tire size, actuation system) and publish torque output.

(c) Develop a large sample lining test that accurately identifies friction level under FMVSS 121 type conditions, identify acceptable ranges, require all suppliers to test and report findings for each lining.

For (b) and (c), establish a monitoring system for compliance.

Presentation by Chuck Greening. Mr. Greening's talk described current rating systems for replacement brake linings. He listed current North American test procedures for brake linings, passenger car brakes, heavy vehicle brakes, and full-size vehicles. SAE J661/J-866 and VESC-V3 test methods do not offer guidance on lining performance on a specific vehicle. Likewise, the SAE J1652 and J2430 do not enable measuring the effects of cooling or the interactions between the front and rear brakes and are not suitable for selection of linings for specific vehicles. Sample sizes vary widely between test methods as well. Greening's $D^{3} E A \circledast$ test uses a double-ended dynamometer to study brake interactions under partitioned front/rear loads characteristic of certain types of vehicles. Other test methods such as FMVSS 121D for air brakes, RP 628, SAE J 1801/1802 were described. He mentioned European test methods for passenger cars (ECE R90, R13) and for heavy vehicles (ISO/DIS 11157), then concluded with a discussion of vehicle-scale tests. The correlation between laboratory tests and vehicle tests is negatively affected by differences in cooling, weight distribution, actuation systems, and surface conditioning. Examples of $\mathrm{D}^{3} \mathrm{EA}$ test data for braking under different front/rear load sharing were given. To preserve compliance should be the goal and clear objectives must be set. Simple and low cost tests are desirable but the results may not be acceptable. Market forces can drive progress on a lining approval system, but that would be slow. The fastest implementation would involve government fiat but that may not result in the best path.

Presentation by Tim Duncan. This presentation described lessons learned from Mr. Duncan's experiences in the voluntary passenger car and light truck friction certification program conducted under the Brake Manufacturers Council (BMC), a product line group of the Motor and Equipment Manufacturers Association. Much of the effort was prompted by a 1987 SAE technical paper by R. Radlinksi ("The Effect of Aftermarket Linings on Brake Efficiency," SAE paper \#870267). The Brake Effectiveness Evaluation Program (BEEP) is based on the SAE J 2430 procedure (disc brakes) and the BMC BEEP model which is vehicle specific. Designed to be an open protocol available to the industry and other interested parties, it involved over 10 years of effort, 50 fully-instrumented vehicle tests, and over 300 dynamometer tests. A multi-level program structure was described. A series of lessons were learned, including:

- There needed to be a continuous commitment and progressive alignment among manufacturers, SAE committees, consultants, and testing laboratories.

- The BEEP model was found to be similar to proprietary brake system models used by Tier 1 suppliers. 
- A good correlation was eventually reached between various dynamometers and test facilities, once repeatable set-up and test practices were established.

- Various facilities are currently running SAE J2430 and BEEP under the same protocol.

- Continuous work by the BMC on promoting and educating on BEEP is giving a common group for vehicle specific effectiveness characterization.

- Technical committees are critical to success as they verify and oversee the validity and consistency of the program.

Presentation by Dennis McNichol. The talk by Dennis McNichol was from an informed fleet operator's perspective on brake lining selection. His fleet, which operates in the northeastern United States, has a wide and varied mission including school buses, straight trucks, and tractor-trailer combinations of various types. Practically all of these vehicles are equipped with 16.5 x 7 'drive axle brakes. He made the point that the OEM spec's may not agree with spec's for what the fleet operator needs in brakes. The same OE chassis may often be equipped with a different body type, necessitating the use of a different brake lining for best performance. One lining 'does not fit all.' McNichol described the strategy of using SAE J 1854 and desired brake force to weight ratios for the vehicle of concern. Required torques (ft-lb) for a given gross axle weight and with desired force/weight ratios are then converted to requirements in in-lbs torque, so that RP 628 lining data can be used for selection. Here is one example from McNichol's talk:

A 17,000 to $20,000 \mathrm{lb}$ axle should produce $4,600 \mathrm{lb}$ of braking force at 40 psi air application pressure. The ratio of brake force to weight for the latter case is $(4,600 / 20,000)=0.23$ (that is, 23\%). Values typically can range from $23-29 \%$.

The J1854 value is expressed for two wheels in units of torque ( $\mathrm{ft}-\mathrm{lb}$ ). Thus, we divide 4,600 by 2 (two wheels/axle) and then multiply the result by the rolling radius of the wheel (inches) to get torque in units of in-lb:

(a) $4,600 / 2=2,300 \mathrm{lbs}$ per wheel

(b) 2,300 lbs x 19 in $=43,700$ in-lbs

For a tandem axle daycab for highway use, with a 20,000 lb Gross Axle Weight and a 0.25 force/weight ratio (corresponding to $25 \%$ ):

(a) 20,000 lbs GAW x $0.25=5,000$ lbs per axle

(b) 5,000 lbs / 2 wheels $=2,500 \mathrm{lb}$ per wheel

(c) 2,500 lb x 19 in $=47,500$ in-lbs

Such calculated values can be compared to published RP 628 values for various linings.

Aftermarket linings are not required to meet FMVSS 121 requirements and there are some bad linings in the marketplace. There are also some good linings available with expected ratings published in the RP 628 list. OEMs cannot be expected to have all the answers and there is a need for a good aftermarket rating system. Users with industry support can best define their needs and make good decisions.

Presentation by J. Fajerski. In contrast to the previous talks which stressed primarily braking force and torque, this presentation also addressed the issue of durability as an element of lining performance. It addressed such issues as; "How long will my lining last? Will my replacement linings last as long as my OEM material? Will my next batch of materials perform the same as the last one? Will my truck stop?", etc. Several different lining criteria were explained. The viewpoint was one of a spectrum of use from the qualification of the lining batch to performance on the truck, thusly: batch $\Rightarrow>$ duty cycle $\Rightarrow>$ brake torque $=>$ brake wear $=>$ vehicle torque $=>$ vehicle wear $=>$ life cycle. The cost of testing and the group 
responsible for doing the testing vary along this line. One-by-one the speaker addressed these different levels of testing, including edge codes, dynamometer testing, and wear life prediction based on a dynamometer schedule that simulates certain vehicle application temperature profiles. Large-scale fleet testing is the best way to verify lining performance throughout its lifecycle, and fleet involvement is essential in the set up phase and in interpreting results. In summary,

- The accuracy and value of predictive tools are in a constant struggle against the cost of testing.

- Fleets cannot underestimate the value of becoming an educated consumer.

- Given application complexity, simple rating systems cannot comprehensively predict a lining's performance.

- Fleets are best served by demanding OE-compliant materials.

Presentation by P. Blau. The purpose and objectives of the NHTSA-sponsored project to develop guidelines for an improved brake lining rating system were described. Despite a history of past efforts by various organizations and industry groups, the current rating tests have still fallen short of answering the need for a simple-to-use, accurate, and widely-applicable lining rating system. Materials have internal structures that depend on their composition and the way they are processed. Viewed in a microscope, brake lining structures reveal a complex, micro-scale mixture of additives and binders. When the lining rubs against the gray cast iron of a drum or disc, new materials with even finer structures are created. This newly-formed material in turn affects the friction and wear behavior of the linings and drums (or discs).

There are several important challenges for those striving to develop a workable lining test protocol. One involves recognizing that materials have properties and characteristics. Basic material properties such as the melting point are intrinsic to the material itself, but characteristics like, the friction coefficient and wear rate, result from a combination of several material properties reacting to the surroundings, as in a drum brake or in a disc brake or in a dynamometer. As a result, the same set of materials can rank in a different order of merit when placed into different kinds of braking and testing systems. Another challenge involves selecting the test conditions themselves. Using a low applied force may produce lining torque rankings in a different order than using a higher one. The same considerations are true for testing at different temperatures and sliding speeds. Thus, any rating that compromises on only one set of lining material test conditions risks producing misleading results, especially for those who use linings at more or less severe service conditions than those represented in the test.

In conclusion, the challenges for developing a widely-useful and accurate brake lining rating scheme, whether for aftermarket, OE, or next-generation brake material evaluations, are formidable. The breakout session, scheduled for the afternoon, is designed to enable fleet operators, equipment producers, lining material companies, and other interested parties help to define the targets and needs for an improved brake lining rating scheme. TMC input will be added to information from other industry meetings and individual inputs to formulate a plan of action and a proposed rating scheme. This scheme will be made available for industry review during the first half of calendar year 2003. 


\subsection{Summary of Afternoon Break-out Session Discussions}

Jim Winsor, Heavy Duty Trucking magazine, presented the general instructions for break-out groups and discussion leaders at the beginning of the afternoon session. As shown in Appendix A, each group consisted of 7 - 9 participants, and the attendance was at least 45, not counting the facilitator. Nine discussion questions were composed before the meeting. These were printed on cards placed on each break-out group's table. The order that the questions were listed on colored cards was different on each table to ensure that at least some of the discussion would be focused on each question during the limited time. As it turned out, however, all groups finished reviewing all the questions within the allotted 45 minute period. When time was up, each group leader summarized his group's response to each of the questions. Jim Winsor facilitated this final review, requesting clarifications as needed to obtain a fair sense of each group's responses.

2.1 List of Discussion Questions. The following nine questions were prepared ahead of time to be discussed during the afternoon break-out session.

1) Do you feel that aftermarket brake lining ratings should be regulated by the federal government?

2) How many operators use RP 628, and if so what's good or bad about it? Does it work for you?

3) Would there be any value to you of a vocation-specific rating system?

4) Should a rating system also be developed for air disc brakes?

5) Should a rating system also be developed for hydraulic disc brakes?

6) In your opinion, which is more important: stopping performance or lining wear life?

7) Is a point-of-sale lining rating sufficient for your needs or would you also appreciate having a good method for in-service inspection?

8) What new or improved method(s), if any, would you favor for in-service brake lining inspection?

9) Do you have any positive or negative comments or reactions to any of the morning speakers' remarks?

2.2 Summary of Discussions. Discussion group leaders summarized their group's opinions at the end of the break-out session. The following documentation resulted from a combination of written notes and review of an audio recording of the session made available by Robert Braswell of TMC. In some cases, specific remarks are repeated (in quotation marks). The names and affiliations of those offering specific comments have been omitted. Instead, specific comments were attributed to fleet operators (abbreviated FLO) and suppliers (SUP)

Question 1) Do you feel that aftermarket brake lining ratings should be regulated by the federal government? 
Summary of Responses) The responders to this question failed to reach a full consensus. Most of groups (which included a number of FLOs) voted 'yes'; but that having been said, they did so with only a modest level of enthusiasm. Those who most favored federal government involvement did so because they saw it as a means to guarantee a more uniform, minimum standard of safety and a means to better regulate foreign-made sources of aftermarket lining products. Some suggested that industry involvement and consensus should be an element of any new federal regulations for linings. Those against federal regulation, or minimal federal involvement, suggested that industry standards (like those developed by TMC) might take less time to put in place. Another comment was that the industry could do it better. Frequent, random checking of product quality/performance was desired. Groups at three of the six tables favored industry-based standards. The vote at one table was 7 for federal involvement and 3 against. That vote tended to reflect the overall sentiment on this question. Participants felt that it may not be possible to regulate effectively if different standards are set for different vocations. Some said: "Let the government keep us honest." The few SUP who don't care so much about their product quality generally are the ones who need to be policed, but it's not necessarily wise to ask the government for help on such matters. The term 'regulation' should not always have the implication: 'regulation by the government.'

Question 2) How many operators use RP 628, and if so what's good or bad about it? Does it work for you?

Summary of Responses) Responses came from a mixture of those with good familiarity with RP 628 and others with little or no knowledge of its details. For example, in one group, there were two FLOs, one who doesn't use it and one who will look into using it because brake linings are a liability issue and the RP 'may be good for determining brake balance.' Another group had three FLOs. One does his own lining testing, one uses RP 628, and the other is willing to start using it. The bad features of RP 628, mentioned in a few groups, include only having a single value for torque, its not being applicable to other than S-cam brakes, and its producing neither fade nor wear information. RP 628 was not felt to be comprehensive enough for a wide range of vocational applications. One group said that those who do use RP 628 do not use it as their sole criterion. One FLO said: "There's nothing good or bad about it [RP 628]." On the other hand he noted that he uses only OE linings. Some said they use it only when appropriate (not for hydraulic disc brakes). One FLO said that he out-sources brake maintenance but will check to see what his maintenance contractor does. There seemed to be a fair number of FLOs who were interested in learning more about RP 628, and we concluded that there is a general need among FLOs for broader education on the technical aspects and use of TMC RP 628.

Question 3) Would there be any value to you of a vocation-specific rating system?

Summary of Responses) This question evoked a variety of responses. Many, if not most liked this idea, but if there were to be different categories, it was not clear what they should be. Some felt 'vocational' was too broad a term. There was a question as to how linings should be sized (rated). Perhaps duty cycle or gross axle weight categories would be better. This might work well for leasing fleets with different kinds of vehicles. One group suggested that separating linings be based on expected lining temperature demand rather than on vocational categories. At least one FLO was against a vocation-specific system. Overall, the response to this question was generally 'yes', but the specifics of how it would be done have yet to be agreed upon, and might involve considerable debate.

Question 4) Should a rating system also be developed for air disc brakes? 
Summary of Responses) The general, nearly-unanimous, response was 'yes,' and some groups issued a 'strong yes.' The comment was made that all the effort should not be spent on "dinosaurs" [referring to S-cam brakes]. On the other hand, the timing and importance of the air disc brake issue had less clear agreement. One group felt that air disc should come second, only after hydraulic disc brakes had been addressed. There was some concern that the differences in disc brake system design would make developing a rating system more complicated. Some advocated working with the medium duty truck community to advance progress in the area.

Question 5) Should a rating system also be developed for hydraulic disc brakes?

Summary of Responses) Overall, there was a sense that ratings for hydraulic brake linings were not a major issue but concerned similar issues as for air disc brakes (that is, they have similar geometry, design features). Therefore, the requirements and rating of hydraulic disc brake linings would not be expected to be largely different from air disc. A representative from a SUP confirmed this assumption, stating that his firm uses essentially the same lining formulations for both. One standard could therefore cover both air disc and hydraulic linings.

Question 6) In your opinion, which is more important: stopping performance or lining wear life?

Summary of Responses) In some sense, this question was ambiguous since both are important in different respects. One group asserted that stopping distance was more important so long as the wear life was adequate. On the other hand, some groups felt they were equally important and there should be no trade-off of one for the other in a 'perfect world'. Most groups gave priority to stopping distance since it is a clear safety issue. One group prioritized stopping distance first, and next came the combination of 'longevity' and price. Another group addressed price as well, stating that the order should be stopping distance, then wear, then price. However, they also claimed that in the real world, it was price first, then wear, then stopping distance. Some noted that the shortest stopping distance was not necessarily the best (liquids, shifting loads) as long as it was within the legal maximum. Some felt that a dual rating system should include both stopping distance and wear.

Question 7) Is a point-of-sale lining rating sufficient for your needs or would you also appreciate having a good method for in-service inspection?

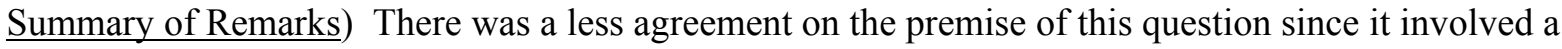
number of related issues. The point-of-sale lining rating has very good potential because inservice inspections may not be as thorough as those given the brakes by a well-qualified shop mechanic. Most thought both point-of-sale and in-service inspections were valuable, but there was less agreement that a performance-based brake tester (PBBT) used in-service was as good as a well-done mechanic's inspection. Point-of-sale ratings may be sufficient as long as they guarantee compliance with out-of-service criteria. While in general a point-of-sale scheme is preferred, a good in-service inspection method would be welcomed by the FLOs. The problem, articulated by some, is that there are too many variables tied up with an in-service inspection method to make it effective. In-service inspections serve a purpose but do not replace point-ofsale inspections.

Question 8) What new or improved method(s), if any, would you favor for in-service brake lining inspection?

Summary of Comments) There are a number of possibilities, but a number of participants admitted to a lack of knowledge of exactly what technologies are currently on the market. No technical 
barriers to a variety of technologies exist, but there are some practical issues. One group suggested that all friction materials should have built in wear monitors (visual), and a seasoned FLO asserted that a great deal of useful information on vehicle condition can be gained by examining use patterns on brake shoes after their removal. Some discussed in-cab brake wear monitors, PBBTs, and infra-red temperature measurements. One FLO called for a simple 30second method to evaluate brake wear in increments of 1/32" (maybe a series of notches?). One participant suggested using PBBTs instead of stroke measurements for determining out-of-service criteria. One group suggested that people who don't maintain brake systems should be penalized, and that in-service inspections should focus on the technical quality of the work, using better training programs to enhance in-service inspection quality.

Question 9) Do you have any positive or negative comments or reactions to any of the morning speakers' remarks?

Summary of Comments) Several groups applauded the good history lesson - done at the right level, but others had mixed reactions. There was a good, non-commercial tone for the material. Some felt that the information was too technical, and others remarked that good technical education is often lacking among those who must deal with brakes in the field. One group felt that the speakers made a good attempt to simplify the technical information. Another group of participants advocated reducing the technical details into more readily understandable information for non-engineers. The need for handouts to accompany the speaker presentations was raised. P. Blau agreed to work with TMC to make copies of the presentations available, either on the TMC website or by another means. One participant wondered why more discussion wasn't devoted to SAE J1802, and suggested: "Someone should go back to UMTRI [the University of Michigan Transportation Research Institute received a DOT grant to analyze sources of error in that test], and tell the world what happened." Finally, some felt that more information should be available to the fleets on drum wear: when to replace them, and how drum wear affects performance.

One group composed their own question for the discussion; namely, "Question 10: What do we want to see in a rating system?" There was a suggestion to expand RP 628 since there was some discomfort in having only one torque value on which to base their lining selection. One suggestion was to add two additional line pressure conditions to consider lower demand (20 psi) and high-demand braking (80 psi) situations. Also, add a fade characterization (like that in FMVSS 121) reporting the difference between required pressure at the beginning of test and that needed for the final application. Finally, there was interest in having some indication of wear of the lining material as well as what the lining is doing to the drum (in terms of wear). It was pointed out by another participant that some of that information is already being collected as a part of FMVSS 121; however, only one torque value (40 psi) is being reported.

A concluding, general discussion was held. In light of the fact that federal safety standards for linings relate mostly to original equipment (OE), it was asked what percentage of trucks were using OE linings at any given time. The consensus answer was about $20 \%$. During the discussion, one OEM engineer noted: "All these processes and plans are great, but what about the human element; how do we train technicians to do everything correctly?" D. Freund, FMCSA indicated that requirements are already placed on individuals who inspect and maintain brakes. Drivers, too, must have proper training to do brake work on the road. There are specific air disc brake-related guidelines for the drivers to have training. Certain self-certification requirements are also in effect. 


\subsection{Fleet Operators Survey}

A one-page survey form was developed with the help of the Heavy Duty Brake Manufacturers Council to collect additional information on brake linings-related issues. With the assistance of TMC, yellow survey forms were inserted into the meeting registration packages of the yellow-badged fleet operators. The format and questions in the survey form are shown below. The first section of the survey was intended to obtain a profile of the responder and the second to solicit opinions, including the use and usefulness of TMC Recommended Practice RP 628.

Help us help you. Please give us your opinion on some important issues concerning brake maintenance and brake lining selection.

First a few questions about your company (please check any that apply):
(a) Fleet composition:
(b) Type of operation:
口 Truck
口 Tractor trailer
(c) Area of operation:
For hire fleet
Private Fleet
Local
Regional
Both

(d) Approximate fleet size:

(e) Do you do your own vehicle maintenance?

$\square$ Yes $\square$ No

- Sometimes do our own, sometimes outsource

(f) Roughly what $\%$ of your vehicles use S-cam drum brakes? What $\%$ air disc?

Now some Opinion Questions about Brakes and Brake Linings.

Using a scale of 1 to 5 , with ' 1 ' = major problem and ' 5 ' = not a problem (circle your answer):

(1) Please rate the following brake-related problems in your fleet:
(a) Electrical / electronics system
(b) Wear - excessive or unpredictable
(c) Noise / vibration
(d) Poor stopping distance
(e) Lubrication issues
(f) Out of adjustment
(g) Component part breakage
(h) Air system
(i) Parking

$\begin{array}{cc}\text { major problen } \\ 1 & 2 \\ 1 & 2 \\ 1 & 2 \\ 1 & 2 \\ 1 & 2 \\ 1 & 2 \\ 1 & 2 \\ 1 & 2 \\ 1 & 2\end{array}$

(2) Which causes would you blame for brake problems?
(a) Training deficiencies
(b) Basic design of the braking system
(c) Maintenance issues
(d) Quality of linings

\begin{tabular}{|c|c|c|c|c|}
\hline \multicolumn{4}{|c|}{ major problem } & not a problem \\
\hline 1 & 2 & 3 & 4 & 5 \\
\hline 1 & 2 & 3 & 4 & 5 \\
\hline 1 & 2 & 3 & 4 & 5 \\
\hline 1 & 2 & 3 & 4 & 5 \\
\hline
\end{tabular}

(3) Which do you use to help select replacement brake linings? (check any or all that apply):
․ Salesman
O OEM
$\square$ Experience
Price
- Same as OE $\quad$ Lining manufacturer
口 TMC Recommended Practice
$\square$ Other
Chosen by maintenance facility

(4) Are you familiar with TMC RP 628 for rating brake blocks?
口 Yes $\square$ No
口 Yes $\square$ No
口 Yes $\square$ No

(5) Do you use RP 628 to select replacement brake linings?

(6) Does RP 628 meet your needs?

If you said ' $N o$ ' to question 6 , then what things about TMC RP 628 would you like to see changed? 
3.1 Survey Responses. Of an estimated 120 yellow-badged registrants, a total of 21 survey forms (18\%) were eventually returned and collected. Responses from the survey were arbitrarily separated into small fleets, medium fleets, and large fleets (see below). The sizes of individual responses ranged from $12-$ 170,000 powered vehicles, and the total number of vehicles represented in the survey (trucks, trailers, and tractors) added up to over 230,600. The distribution of fleet sizes was:

$\begin{array}{lll}\text { Small fleets (up to } 100 \text { powered vehicles }) & 6 & \text { (28\% of the total) } \\ \text { Medium fleets }(101-1000 \text { powered vehicles }) & 5 & (24 \% \text { of the total) } \\ \text { Large fleets (over } 1000 \text { powered vehicles }) & 10 & \text { (48\% of the total) }\end{array}$

A more detailed breakdown is shown in Figure 1. About half of the responses (10) came from fleets having between 501 and 5000 vehicles.

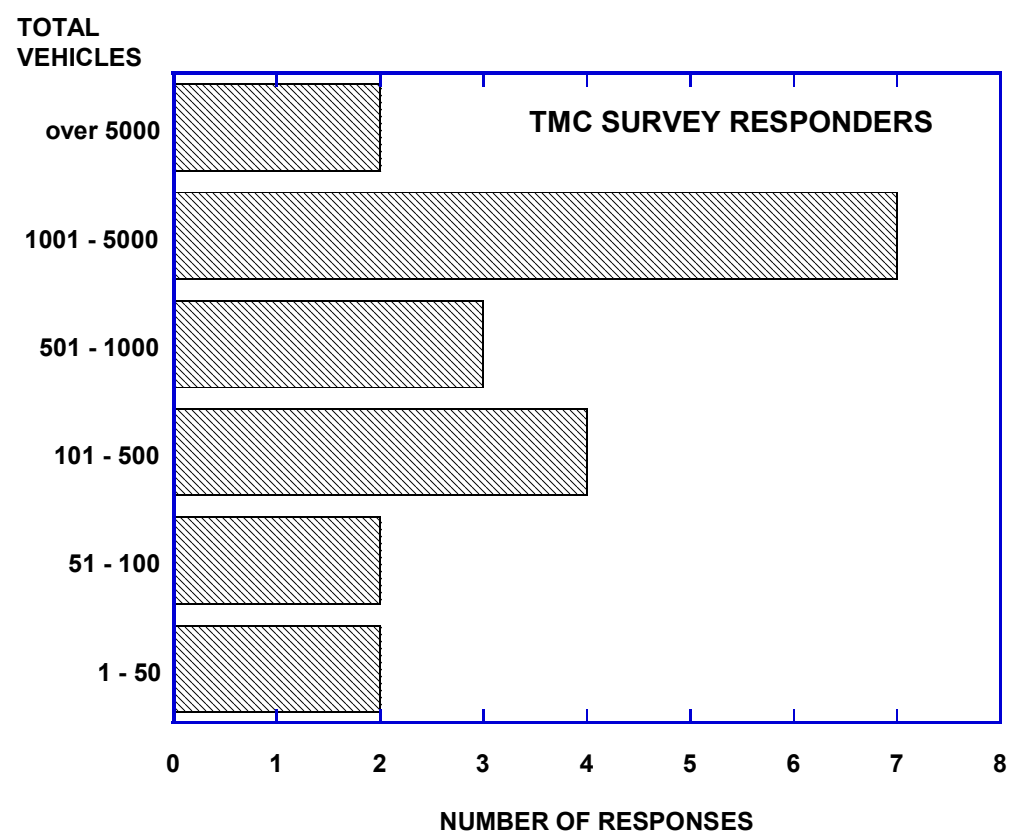

Figure 1. Distribution of fleet sizes responding to the fleet survey. One respondent did not indicate a size and was left out of the distribution.

Responses to the first section of the survey revealed the operational profiles. In some cases, a response might have included two choices, for example: a fleet may have both regional and national operations. In terms of the type of operation, most were either for hire or private. Medium and large fleets tended to be regional or national, as one might expect. By far, most did their own maintenance work. Table 1 summarizes the responses to the general profile questions.

The second part of the survey were opinion questions related to the relative importance of brake-related problems. These were based on a scale of 1 to 5 with 1 being most important and 5 the least. There was no obvious trend with respect to fleet size, so all the answers to questions 1(a) - (i) were combined into a single summary table (see Table 2). 
Table 1.

Responses to Profile Questions

\begin{tabular}{|l|l|c|c|c|}
\hline Category & Response & Small & Medium & Large \\
\hline \hline Operation type & For hire & 4 & 3 & 4 \\
\hline & Private & 2 & 2 & 4 \\
\hline & $\begin{array}{l}\text { Other (owner/operator, } \\
\text { lease/rental) }\end{array}$ & 0 & 1 & 1 \\
\hline \hline Geographic & Local & 2 & 1 & 0 \\
\hline & Regional & 4 & 1 & 5 \\
\hline \hline $\begin{array}{l}\text { Maintenance } \\
\text { preference }\end{array}$ & National & 0 & 4 & 5 \\
\hline & Do our own & 5 & 5 & 6 \\
\hline & Outsource & 1 & 0 & 0 \\
\hline \hline Type of brakes & $\begin{array}{l}\text { Sometimes do our own, } \\
\text { sometimes outsource }\end{array}$ & 0 & 0 & 4 \\
\hline & $100 \%$ drum/shoe & 5 & 3 & 4 \\
\hline & $70 \%$ drum/shoe $98 \%$ drum/shoe & 1 & 0 & 2 \\
\hline & $95 \%$ hydraulic disc/5\% drum & 0 & 2 & 2 \\
\hline & $\begin{array}{l}100 \% \text { disc on steer, 30\% disc on } \\
\text { drive, } 70 \% \text { S-cam on drive }\end{array}$ & 0 & 0 & 1 \\
\hline & & & & \\
\hline
\end{tabular}

Table 2.

Survey Question 1: Relative Importance of Brake-Related Problems

(number of responses in each category)

\begin{tabular}{|l|c|c|c|c|c|}
\hline \multicolumn{1}{|c|}{ Problem Type } & Major & & & & No prob. \\
& $\mathbf{1}$ & $\mathbf{2}$ & $\mathbf{3}$ & $\mathbf{4}$ & $\mathbf{5}$ \\
\hline \hline (a) Electrical / electronics system & 0 & 2 & 8 & 8 & 3 \\
\hline (b) Wear & 3 & 1 & 8 & 5 & 3 \\
\hline (c) Noise or vibration & 0 & 0 & 7 & 7 & 7 \\
\hline (d) Poor stopping distance & 1 & 2 & 3 & 8 & 7 \\
\hline (e) Lubrication & 0 & 2 & 8 & 6 & 5 \\
\hline (f) Out of adjustment & 0 & 6 & 6 & 7 & 2 \\
\hline (g) Part breakage & 1 & 1 & 7 & 6 & 5 \\
\hline (h) Air system & 1 & 3 & 6 & 7 & 4 \\
\hline (i) Parking brake & 1 & 0 & 5 & 10 & 5 \\
\hline
\end{tabular}

Considering the top category of importance 'wear' was listed most often, but 'out of adjustment,' 'air system,' and 'poor stopping distance' also received marks in the higher categories. Significantly, 'out of adjustment' also had the least votes in the 'not a problem' category and most felt it represented at least a moderate problem area. Roughly $30 \%$ listed poor stopping distance as a moderate to major concern, and lubrication issues also received attention in the moderate range of problem areas. 
Survey question 2 dealt with causes for brake-related problems. Table 3 summarizes the survey responses, again from $1-5$ in order of importance. As for Table 2, all fleet sizes were grouped together in summarizing the responses.

Table 3.

Survey Question 2: Fixing the Blame for Brake-Related Problems

\begin{tabular}{|l|c|c|c|c|c|}
\hline \multicolumn{1}{|c|}{ Cause } & Major & & & & No prob. \\
\hline Training deficiencies & $\mathbf{1}$ & $\mathbf{2}$ & $\mathbf{3}$ & $\mathbf{4}$ & $\mathbf{5}$ \\
\hline Basic design of the brake system & 1 & 6 & 10 & 2 & 2 \\
\hline Maintenance issues & 1 & 6 & 1 & 8 & 4 \\
\hline Lining quality & 2 & 2 & 8 & 6 & 4 \\
\hline
\end{tabular}

'Training deficiencies' was listed among the top three categories by 17 out of 21 responders. More than $1 / 3$ considered design of the brake system an issue of moderate to high importance, but only 9 placed linings in the top 3 categories of importance. Maintenance issues were of at least some importance to 17 out of the 21 responders.

Considering the issue of lining quality in question 2, the wording of this question does not directly address the issue of lining selection. More than half of the responders apparently felt that linings of adequate quality are available, but the real question should be how convenient it is to select linings and to locate a reliable source for them. That issue was addressed in question 3. Multiple responses to that question were possible so the total did not add up to 21 responses. Table 4 summarizes the responses to question 3. By far, experience plays a major role in lining selection, but most of the responders also rely on recommendations from lining manufacturers. The TMC Recommended Practice helps 8 out of 21 to make lining selections.

Table 4.

Survey Question 3: Which Do You Use to Help Select Replacement Brake Linings?

\begin{tabular}{|l|c|}
\hline \multicolumn{1}{|c|}{ Choice } & Responses \\
\hline \hline Salesman & 2 \\
\hline Original equipment manufacturer & 3 \\
\hline Experience & 17 \\
\hline Price & 7 \\
\hline Use same as on original equipment & 3 \\
\hline Lining manufacturer & 13 \\
\hline Chosen by maintenance facility & 5 \\
\hline TMC Recommended Practice & 8 \\
\hline Other (service/support, parts availability, training) & 1 \\
\hline
\end{tabular}

As discussed by the invited speakers, TMC Recommended Practice 628 was designed as a useful, but not necessarily the ultimate method for aftermarket brake lining selection. Therefore in the final series of questions, we asked to what extent RP 628 was known and used. The responses to that question are summarized in Table 5. In this case, the answers are broken out by size of fleet to see whether there was any trend. 
Table 5.

Survey Questions 4-6: Familiarity and Use of TMC RP 628

\begin{tabular}{|l|c|c|c|c|c|c|}
\hline \multicolumn{1}{|c|}{ Question } & \multicolumn{3}{c|}{ "Yes" } & \multicolumn{3}{c|}{ "No" } \\
\cline { 2 - 7 } & Small & Medium & Large & Small & Medium & Large \\
\hline \hline Are you familiar with RP 628? & 4 & 2 & 10 & 2 & 3 & 0 \\
\hline Do you use RP 628? & 2 & 2 & 7 & 4 & 3 & 4 \\
\hline Does RPM 628 meet your needs?* & 3 & 2 & 4 & 1 & 1 & 5 \\
\hline
\end{tabular}

* One large fleet responder answered "yes" and "no" and was added to the scores in both yes and no boxes.

Overall, 16 of 21 were familiar with RP 628 and 11 of those 16 used it at least in part to help select linings. As was apparent in the discussion period, many used RP 628 but not necessarily as the sole criterion for selecting linings. In some cases, the conditions of RP 628 simply did not apply to the vocational use of specific fleets (for example, hydraulic disc).

3.2 Additional Comments Regarding RP 628. A number of the responders offered additional written comments on their survey forms in regard to question 6 on RP 628. These are reproduced below with minimal or no editing. The code letter in brackets [ ] indicates the size category (Small, Medium, Large) of the fleet operator who offered the comment.

"It should be expanded to include more axle ratings." [S]

"We don't know anything about this." [M]

"Not familiar with it and did not answer question \#6. I will go back and make myself familiar with RP 628.” [M]

"RP 628 is not updated enough. I also question the oversight of the SAE Performance Institute in overseeing this project. It appears that most of those submitting test results are submitting tests performed on their own dyno's which have been certified by the Performance Institute. These tests are not being performed by an independent 'third party.' Originally I thought that lining was going to be 'pulled off the shelf' and periodically retested to make sure that the manufacturer's product is consistent. This does not appear to be happening." [L]

"Brake blocks can cross over from high-end to low-end. When buying brakes at various locations, you should be able to get an exact match. This does not happen now. I would also like to see a spec for approximate life expectancy." [L]

"RP 628 does not address hydraulic disc brake pads." [L]

"We do field testing of linings. We look at lining life, drum life, and compatibility with disc brakes. We check heat off brakes along with application pressure and timing." [L]

"Yes/No (as regards meeting our needs). As with most RP's we use them as a benchmark to our current practices, also to see which practices and procedures need to be modified. Understanding that change sometimes comes slowly - considering: procurement vendors, outsource contractors, training, contractural agreements, etc. at over 60 facilities." [L]

"We do not buy brake linings on price. When you use quality vendors, it is not a major issue - but RP 628 is not complete or extensive enough. It is a great first step, but we need to push forward." [L] "RP 628 deals with line-haul more than vocational." [L] 


\subsection{Conclusions}

The attendance and level of enthusiasm at the Technology and Maintenance Council (TMC) workshop in Charlotte, North Carolina, confirmed the notion that, after more than 30 years of technical effort, a great deal of continuing interest remains in the development of a better system for rating truck brake linings. In the morning session, a panel of invited speakers presented a balanced overview of the development of lining test methods and how a fleet manager can approach lining selection. Speakers attempted to distill their technical details into a comprehensible form, but a few in the audience still felt that some of the talks were too technical. Nevertheless, those who attended generally felt that they took away new information about brake performance and testing that they could use.

The afternoon discussion session involved more than 45 participants from the trucking industry and several government agencies. Each of the six break-out groups debated nine opinion questions. There were mixed feelings regarding the need for the U.S. government to regulate or specify performance criteria for aftermarket truck brake linings, but the overall sentiment was that such regulations would help to level the playing field among suppliers in the linings aftermarket, and that any government-mandated standards should be developed with strong industry involvement. A single rating system, applicable to all trucks, seems impractical in light of the varying demands for different vocational vehicles. Some kind of service and wear rating differentiation is needed so that appropriate criteria can be applied when qualifying linings for different uses. It was suggested that heat load would be one way to differentiate between different levels of service severity. It was also felt that discs (both air and hydraulic) were important enough for the future of U.S. trucking to consider how these could be included downstream as the lining rating system develops.

Despite a disappointingly low response to the survey of fleet operators (21 returns out of 120 fleet registrants), the general findings seem consistent with the issues surfacing in other sources of industry information. The vast majority of fleets $(>90 \%)$ use S-cam type drum brakes on tractors, straight trucks, and trailers, but air disc brakes are beginning to make some in-roads on steer axles of some fleets. Fleet operators tend to do their own brake maintenance, and most rely mainly on a combination of experience and vendor information to select replacement linings. A substantial number of fleet operators do not know too much about TMC recommended practice RP 628, and those who do use it as a means to select aftermarket lining products do not use it as the sole criterion on which to base their decisions.

In summary,

(1) Developing a new aftermarket friction brake lining system is important to the trucking industry.

(2) Government regulation or standards for aftermarket linings would help to level the playing field as long as industry participated in the development.

(3) Some kind of differentiation is needed in the lining rating scheme to account for the requirements of different types of service.

(4) A wear rating of some kind would be helpful, but finding a practical one that does not mislead the user will be a challenge.

(5) Emphasis should be on drum brakes initially, with a view toward disc brakes in the future. 


\subsection{Acknowledgements}

The author wishes to acknowledge the help and valuable advice provided by Jim Britell (DOT/NHTSA) and Jim Lawrence (Heavy Duty Brake Manufacturers Council, HDBMC). The efforts of the invited speakers, listed in Section 1, are greatly appreciated, as is the help of Jim Winsor, Heavy Duty Trucking magazine, for effectively facilitating the break-out session. The advice of members of the HDBMC was helpful in constructing and refining the fleet operators survey. Robert Braswell, Technical Director of $\mathrm{TMC}$, was most helpful in coordinating the scheduling, recording, and publicity of the linings workshop, as was Welling Watts, also of TMC. John J. Truhan, Jr., (University of Tennessee - Knoxville) helped in many aspects of this activity, including serving as a discussion leader, helping to tabulate the survey results, and as a proof-reader for this report. The contractual work of which this report is a part is sponsored by the U.S. Department of Transportation under interagency agreement DOE 2334-R486-A1 with the US Department of Energy under contact DE-AC05-00OR22725 with UT-Battelle, LLC. 


\section{Appendix A: Discussion Group Members}

Discussions we led in part by speakers from the morning session and other volunteers. Most provided lists of those within their groups. Clearly, the groups exhibited a range of lining suppliers, fleet operators, equipment manufacturers, research and testing laboratories, and government organizations. The group leader's name is underlined.

\begin{tabular}{|c|c|}
\hline Dennis McNichol & Dennis NationaLease \\
\hline Brent Armentrout & Haldex \\
\hline John Thomson & Carlisle \\
\hline Curtis Cummings & Federal Express Freight East \\
\hline Alex Billings & Federal Express Freight East \\
\hline Steve Shaffer & Battelle \\
\hline Joe Stianche & Sanderson Farms \\
\hline Mark Austin & Federal Express Freight East \\
\hline John Truhan & University of Tennessee \\
\hline$\overline{\text { Ken Kelley }}$ & Walther EMC \\
\hline John Hall & Webb Wheel Products, Inc. \\
\hline Ken Post & FST Logistics \\
\hline Fred Hopper & TMD Friction \\
\hline Deborah M. Freund & Federal Motor Carrier Safety Administration (U.S. Gov.) \\
\hline A. R. Hummel & Federal Mogul \\
\hline Peter Blau & Oak Ridge National Laboratory \\
\hline Jim Herman & Perdue, Inc. \\
\hline Jerry Rousseau & Perdue, Inc. \\
\hline Parker Hilands & Haldex Brake Systems \\
\hline Earl Herweck & Arvin Meritor \\
\hline Ronnie Kinsella & TruckPro \\
\hline Joe Smith & TruckPro \\
\hline Tim Duncan & Link Test Labs \\
\hline Doug White & Dunbar \\
\hline John Hawker & Dana \\
\hline Tom Sheikh & Carlisle \\
\hline Greg Meller & Jevic Transportation \\
\hline Jim Clark & Dana \\
\hline David Foster & Southeastern Freight Lines \\
\hline Jim Lawrence & Heavy Duty Brake Manufacturers Council \\
\hline Richard Diemer & BrakePro \\
\hline Jay White & Hendrickson \\
\hline James Rushe & Hendrickson \\
\hline Alan Matsumoto & Carlisle \\
\hline Susie Braman & TruckPro \\
\hline Randy Petresh & Haldex \\
\hline Chuck Greening & Greening Labs \\
\hline
\end{tabular}


Roger Duff

Jim Fajerski

Jim Britell

Jim Mollard

Bill Mild

Gary Ganaway

Kevin Tomlinson

Tom Berg
Alvan Motor Freight

Federal Mogol

National Highway Traffic Safety Administration (U.S. Gov.)

Federal Mogul

Federal Mogul

Arvin Meritor

Motor Carrier Service, Inc.

Heavy Duty Trucking Magazine 
ORNL/TM- 2003/24

\section{INTERNAL DISTRIBUTION}

1-5. P. J. Blau

6-7. H. E. Knee (NTRC)

8-10. D. R. Johnson

11. A. E. Pasto

12. E. E. Bloom
13. R. E. Ziegler (NTRC)

14. J. J. Truhan (ORNL/UT)

15. Central Research Library

16. ORNL Laboratory Records - RC

17. ORNL Laboratory Records - OSTI

\section{EXTERNAL DISTRIBUTION}

18-23. C. J. Britell, U.S. Dept. of Transportation, NHTSA Research, 400 7th St. SW (Room 6220-L), Washington, DC 20590

24-26. D. Perrin, U.S. Dept. of Transportation, NHTSA Research, 400 7th St. SW (Room 6220-L), Washington, DC 20590

27. Sidney Diamond, U.S. Dept. of Energy, Forrestal Bldg. EE-2G, 1000 Independence Ave. SW, Washington, DC 20585

28. Paul Abelson, Land Line, 2629 Alta Court, Lisle, IL 60532

29. Eric Amlin, Forest Engineering Research Institute of Canada, 2601 East Mall, Vancouver, BC, CANADA V6T $1 Z 4$

30. Arne Anderson, Link Engineering Co., 43855 Plymouth Oaks Boulevard, Plymouth, MI 48170

31. Brent A. Armentrout, Haldex Brake Systems Division, Friction Product Center, 629 Copperfield Lane, Tipp City, OH 45371

32. Russell L. Armer, Brakepro Inc., 101 Brown Farm Road, Cartersville, GA 30120

33. Ronald D. Bailey, Bendix Commercial Vehicle Systems, LLC, 901 Cleveland Street, Elyria, OH 44035

34. Rena Basch, Ford Motor Company - Science Research Lab, P. O. Box 2053 MD 2115, Dearborn, MI 48121-2053

35. Timothy A. Blubaugh, Freightliner, LLC, 4747 N. Channel Avenue, Portland, OR 97217-7699

36. Allen Born, Alumax Engineered Metal Processes Inc., 2404 Dr. F. E. Wright Drive, Jackson, TN 38305

37. Denis Boucher, Crash Avoidance Research, Transport Canada, Safety and Security, 330 Sparks Street, Tower "C", Ottawa, Ontario CANADA, K1A 0N5

38. John Bradley,Auto-Motivation, Ltd., Transportation Consulting, 2127 Cambridge Park Court, Wheaton, MD 20902 
39. Robert Braswell, Technology and Maintenance Council (TMC), 2200 Mill Road Alexandria, VA 22314

40. Leonard Buckman, Buckman Consulting Services, Inc., 2258 Shoreline Drive Brighton, MI 48114

41. Vern Caron, Wabash International, 5725 Venture Park Road, Kalamazoo, MI 49009

42. Daniel E. Carter, Product Systems \& Components, Great Dane Trailers, P. O. Box 67, Savannah, GA 31402-0067

43. Anne-Claire Christiansen, Vehicle Braking \& Stability Research, Battelle, 505 King Avenue, Columbus, $\mathrm{OH}$ 43201-2693

44. James R. Clark, Foundation Brakes \& Wheel Alignment, Dana Corporation, Spicer Heavy Axle \& Brake Division, P.O. Box 4097, Kalamazoo, MI 49003-4097

45. Paul J. Clark, TSE Brakes, Omnibrake, 3183 S. Parkway Drive, Fresno, CA 93725

46. P.E. Richard J. Conklin, VEMM Engineering Group, Bendix Commercial Vehicle Systems, LLC, 901 Cleveland Street, Elyria, OH 44035

47. Chris Demas, Engineering Design, Kenworth Truck Company, P.O. Box 1000 (98083-1000), Kirkland, WA 98033

48. Dennis McNichol, Dennis NationaLease, 6951 Norwitch Drive, Philadelphia, PA 19153

49. Richard B. Diemer, OEM Sales, Brakepro, LTD., 1612 Callie Way Drive, Franklin, TN 37064

50. Jerry Dodd, BMY Wheeled Vehicles, 700 Kirkpatrick Road, Malvern, AR 721047230

51. Tim Duncan, Testing Services, Link Testing Laboratories, Inc., 13840 Elmira Avenue, Detroit, MI 48227-3017

52. Mike Dunn, NATC - Nevada Automotive Test Center, P. O. Box 234, Carson City, NV 89702

53. D. Scott Eberle, Carlisle Industrial Brake and Friction, 1031 East Hillside Drive Bloomington, IN 47401-6597

54. Michael O. Ellis, Commercial Vehicle Inspection Unit, Dept. of California Hwy Patrol, Enforcement Services Division, 444 N. 3rd Street, Suite 310, Sacramento, CA $95814-0228$ 
55. Dave Engelbert, Haldex Brake Systems, 10930 N. Ponoma Avenue, Kansas City, MO 64153

56. Greg Ewell, Wheel-End Equipment, Hayes-Lemmerz International, Inc., 15300 Centennial Drive, Northville, MI 48167

57. James Fajerksi, Federal Mogul Corp., 26555 Northwestern Hwy, Southfield, MI 48034

58. Bennie L. Farmer, Telanon, Inc. - ROADRisk - ADAS Products, 2223 Stone Road, Ann Arbor, Ml 48105

59. George R. Fenske, Tribology Section, Argonne National Laboratory, $9700 \mathrm{~S}$. Cass Ave., ET/212, Argonne, IL 60439

60. Marty Fletcher, Tech Maintenance \& Training, US Xpress, 4080 Jenkins Road, Chattanooga, TN 37421

61. Alan R. Freigang, Engineering, Advanced Chassis Control Systems, Dana Corp., Ride \& Control Systems Division, P.O. Box 4097, Kalamazoo, MI 49003-4097

62. Bryan Funke, OE Sales \& Application Engineering, Federal-Mogul Corp., Friction Products Group, 44064 Plymouth Oaks Boulevard, Plymouth, MI 48170

63. John Gemender, Navistar International, 2911 Meyer Road, Fort Wayne, IN 46801-1109

64. S. William Gouse III, Engineering, American Trucking Associations, 2200 Mill Road, Alexandria, VA 22314-4677

65. Charles W. Greening, Jr., Greening Test Labs, 19465 Mt. Elliot Avenue, Detroit, MI 48234-2786

66. John C. Hall, Product Engineering, Webb Wheel Products, Inc., 2310 Industrial Drive, S.W., Cullman, AL 35055

67. Noble Hamilton, 55 Brake Company, P.O. Box 813, Eagle, ID 83616-0813

68. Stephen F. Hampson, WABCO North America Inc., 2550 S. Telegraph ,Suite 104, Bloomfield Hills, MI 48302

69. Bob Hannon, ArvinMeritor, 2135 West Maple Drive, Troy, MI 48084

70. Jerry Hendricks, Medium Truck Engineering, Vehicle Engineering Dept., Ford Motor Company, Product Development Center, 20901 Oakwood Boulevard, Cube 2J-E47, MD 227, Dearborn, MI 48124-4077

71. Kevin Judge, Raybestos Brakes, 4400 Prime Parkway, McHenry, IL 60050

72. D.J. Just, Brakes, Chassis Systems Engineering, International Truck and Engine Corporation, Truck Group, P.O. Box 1109, Fort Wayne, IN 46801-1109 
73. Ken Kelley, Walther EMC, 3501 Shotwell Drive, Franklin, OH 45005

74. Fred Kerrick, Michelin North America, 4301 Fieldspoint Place, Lexington, KY 40514

75. Jim Lawrence, Motor and Equipment Mfr Assoc., 10 Laboratory Drive, Research Triangle Park, NC 27709

76. Alex C. Lee, Sound \& Vibration Lab, GM Corp Engineering Technical Center, 1435 Cincinnati St MS/E-521, Dayton, OH 45401

77. Michael R. Leipold, Systems Engineering, Volvo, 7900 National Service Rd (M/S TC/1-35), Greensboro, NC 27409-9416

78. Paul D. Levering, Technical Services, Webb Wheel Products, Inc., 2310 Industrial Drive, S.W., Cullman, AL 35055

79. Klaus Lindemann, New Technology Development, Meritor WABCO, Vehicle Control Systems, 3331 W. Big Beaver Road, Suite 300, Troy, MI 48084

80. Brian Lindsay, Ferodo America Inc., 1 Grizzly Lane, Smithville, TN 37166-2810

81. Roy Link, Link Engineering Company, 43855 Plymouth Oaks Boulevard, Plymouth, MI 48170-2585

82. Don Long, Product Engineering, R.H. Sheppard Company, Inc., 101 Philadelphia Street, P. O. Box 877, Hanover, PA 17331-0877

82. Carl Mannerfelt, Volvo Trucks North America, Inc., 7900 National Service Road, Greensboro, NC 27402-6115

84. Steve Maxon, Averitt Express, P. O. Box 100342, Nashville, TN 37224-0342

85. Jim McClelland, Control System \& Air Disc, Bendix Commercial Vehicle, Systems, LLC, 901 Cleveland Street, Elyria, OH 44035

86. William M. Mild, Commercial Vehicle Friction Products, Federal-Mogul Corporation, Friction Products Group. 9151 Latty Avenue, Berkeley, MO 63134

87. Ayumu (Alan) Miyajima, Automotive Products Research Laboratory, Hitachi America, Ltd., 34500 Grand River Avenue, Farmington Hills, MI 48335

88. James W. Mollard, Federal-Mogul Corporation, Friction Products Group, 44064 Plymouth Oaks Boulevard, Plymouth, MI 48170

89. Yngve Naerheim, Rockwell International Science Center, 1049 Camino Dos Rios Thousand Oaks, CA 91360

90. Alex Neyman, MTA New York City Transit, Dept. of Buses, 25 Jamaica Avenue, Room 22A, Brooklyn, NY 11207 
91. Dacio Paul, Brake Systems Engineering, ArvinMeritor, Commercial Vehicle Systems, 2135 West Maple Drive, Troy, MI 48084-7186

92. Chad Pearson, Noregon Systems, 500 Shepherd Street, Suite 300, WinstonSalem, NC 27103

93. Randy Petresh, Haldex Brake Systems, 10707 N.W. Airworld Drive, Kansas City, MO 64153-1215

94. Dick Radlinski, Radlinski and Associates, 3143 County Road 154, E. Liberty, OH 43319

95. S. K. Rhee, Honeywell - Friction Materials, 1746 Thunderbird Road, Troy, MI 48084

96. Russell Rike, ArvinMeritor, Kelly Engineering Resources, 2172 Simison Road, Spring Valley, $\mathrm{OH} 45370$

97. Sam Riley, Goodyear Tire \& Rubber Co., P. O. Box 570, Union City, TN 38281

98. P.E. Richard A. Romer, Electronic Products, Meritor WABCO, Vehicle Control Systems, 3331 W. Big Beaver Road, Suite 300, Troy, MI 48084

99. Gary R. Schultz, GR Schultz Consulting LLC, 9920 Springwood Drive, Kalamazoo, MI 49009-9367

100. William J. Schumacher, AK Steel Corporation, Research, 705 Curtis Street Middletown, $\mathrm{OH}$ 45043-0001

101. Frank Severini, Consolidated Metco, Inc., P.O. Box 83201, Portland, OR 97203

102. Steve Shaffer, Battelle Columbus Laboratories, 505 King Avenue, Columbus, OH 43201

103. William A. Singleton, Honeywell CVS, 901 Cleveland Street, Elyria, OH 44036

104. P.E. Richard W. Siorek, US Army Tank-Automotive and Armaments Command AMSTA-TR-N/272, Warren, MI 48397-5000

105. Roger L. Smith, Systems Engineering, Robert Bosch Corp, Automotive Group 401 North Bendix Drive, South Bend, IN 46628

106. Stephen C. Spata, , National Truck Equipment Association, 37400 Hills Tech Drive, Farmington Hills, MI 48331-3414

107. Denny R. Stephens, Heavy Vehicle Technology Group - Transportation Battelle, 505 King Avenue, Columbus, OH 43201-2693

108. Joseph Stianche, Sanderson Farms, Inc., P. O. Box 988, Laurel, MS 39441 
109, P.E. Stanley L. Stokes, Engineering, Forensic, Management Consulting, BRAKETEC, 17400 Placita Palmilla, Sahuarita, AZ 85629-9449

110. Walt Stringham, Bosch Braking Systems, 401 N. Bendix Drive, South Bend, IN 46634-4001

111. James E. Szudy, Vehicle Systems, Bendix, 901 Cleveland Street, Elyria, OH 44035

112. Travis Taylor, Carlisle Motion Control Industries, Inc., 4040 Lewis and Clark Drive, Charlottesville, VA 22911

113. John Thompson, Motion Control Industries, Inc., 2945 Hunters Hill, Kalamazoo, MI 49048-6113

114. Richard J. Toner, Toner Associates, 5446 Ottawattamie Drive, Pentwater, MI 49449-8506

115. Jim Trainor, J. T. Trainor \& Assoc., 8 Rivendell, Shelton, CT 06484-4331

116. Chuck Trueman, Paccar Technical Center, 12479 Farm to Market Road Mount Vernon, WA 98273

117. P.E. John A. Urban, Brake Engineering, Meritor Heavy Vehicle Systems, LLC, 2135 W. Maple Road, Troy, MI 48084-7186

118. Bill Van Horn, Noregon Systems, 500 Shepherd Street, Suite 300, WinstonSalem, NC 27103

119. Vinod Vemparala, Wellman Friction Products Co., 920 Lake Road, Medina, OH 44256

120. Nathan C. Ware, Ware Associates, PMB-314, 101 Washington, Grand Haven, MI 49417-1354

121. Jay White, Components Engineering, Hendrickson International, 2070 Industrial Place, S. E., Canton, OH 44707

122. Jim Winsor, Heavy Duty Trucking, 38 Executive Park, Suite 300, Irvine, CA 92614

123. Steven F. Wyss, Automotive Products Division, Ferodo America Inc., 1 Grizzly Lane, Smithville, TN 37166

124. Roy S. Zietlow, Chassis Systems Engineering, International Truck and Engine Corporation, Truck Group, 2911 Meyer Road (46803) - P.O. Box 1109 Fort Wayne, IN 46801-1109 